\title{
Reading Development in L1 and L2: An Investigation of Information Recall among $7^{\text {th }}$ Graders of Limpopo
}

\author{
Pheladi Florina Fakude
}

\author{
North-West University (Vaal Triangle Campus), School of Languages, RSA, \\ 24474134@nwu.ac.za
}

\section{Doi:10.5901/mjss.2014.v5n23p1030}

\section{Abstract}

Reading development achievement in South Africa is generally cited to be low compared to the rest of the world. While general reading challenges and low reading proficiencies have been adequately expressed in the literature, very little is said about the performance of learners in rural and peri-rural areas of the Limpopo Province, who are trying to cope with two distal language systems. In order to address this issue, this study sought to investigate the reading achievement of Limpopo learners using the reading scores of 150 learners who took a reading comprehension test in order to report on their information recall results. Descriptive statistics were used to answer research questions. The results of the study revealed that the peri-rural school performed better in English than in Sepedi, the two rural schools performed well in their mother tongue. The results further indicate similar performance levels for the two rural schools (different dialects). The results in the peri-rural school thus support the commonly held assumption that readers develop higher proficiency in English than they do in African languages (peri-rural school) (Pretorius \& Mampuru, 2007). Suggestions for bi-literacy development, emphasising reading achievement in the home language, are offered for adaptations in comparable contexts.

Keywords: Recall, second language (L2) and First language (L1), Working memory (WM), Reading Comprehension

\section{Introduction}

In the past recall tasks have been used to explore a number of aspects including measuring the level of learner's reading comprehension. The research on information recall is therefore discussed within the spectrum of under-developed reading literacy, which has been recognised as one of the main challenges facing developing countries around the world (Paran \& Williams, 2007; Bernhardt, 1998; Pretorius \& Mampuru, 2007). Apart from a host of other variables, such as print-poor environments, South Africa lacks a reading culture (Sisulu, 2004). The basic obstacle to reading literacy development in South Africa and other countries (Eritrea and Zambia) is the inability of learners to comprehend school reading materials (Asfaha, Bechman, Kurves \& Kroon, 2009; Bernhardt, 1998:9). Similar results were found with regard to Grade 6 learners who scored $28 \%$ in their Annual National Assessment for literacy (ANA, 2011). To date, very few published studies have investigated the link between information recall and reading comprehension in both L1 (Northern Sotho) and L2 (English).

Notably the array of challenges experienced in reading comprehension can be explained and resolved by an understanding of the language in terms of transfer (Cummins, 2000), both empirical and theoretical apparatuses (recall tasks) (Snowling \& Hulme 2007), the recall tasks that predict and account for reading development, and an investigation into the link between information recall and reading comprehension. This breakthrough of the previous four findings accounts for many literacy specialists paying attention to the interface between L1 and L2 in order to explain reading development among emerging and advanced readers from across the world (e.g., Garcia, 2007; McLaughlin, 1984). From the theoretical proposition of Cummins's Linguistic Interdependence Hypothesis (1979; 2000), it is expected that certain levels of skills acquired in one language should be transferable to another language, and that preferred order is skills being L1 skills transferred to L2. However, the results of empirical data on the direction of transfer in Africa differ markedly from those of the developed countries where Cummins conducted his research (e.g., Cummins, 1979).

In the study the linguistic skills that are important for the success of the learner's reading development levels this includes: (a) Decoding skills, which refer to the process whereby print symbols or codes are recognised and translated or de-coded into language (Pretorius \& Lephalala, 2011). It is important that the reader's knowledge of the sound-letter relationship in the alphabetical writing system as well as his or her ability to recognise the words rapidly accurately are implemented and emphasised; (b) Vocabulary knowledge, which refers to the amount of vocabulary that learners cover while they read for comprehension. This promotes the ability to interact with the text so that existing knowledge can be 
modified or new awareness and knowledge of the process can be acquired (National Reading Panel, 2000). In addition, other studies are in support of a direct relationship between vocabulary knowledge and reading comprehension (CuenceSanchez, 2008). The results of the study conducted by Cuence-Sanchez, (2008) suggest that the degree of vocabulary coverage required depends on the degree of comprehension. For the advancement of the participants and to satisfy the measurement instruments, $60 \%$ comprehension is considered to be adequate, whereas $95 \%$ of the coverage would be sufficient (Schmitt, Jiang \& Grabe, 2011). Vocabulary knowledge is this sufficient for comprehension; therefore, if learners cannot read, it implies that they are not familiar with the vocabulary. According to the findings of this study, vocabulary knowledge is an essential requirement for good comprehension, and it interacts with other reading skills in facilitating comprehension (Schmitt, Jiang \& Grabe, 2011).

Many researchers have concluded that working memory capacity exerts a causal role in reading skills, that is, a greater working memory capacity allows the reader to complete more of the cognitive processes involved in reading (Alptekin \& Ercetin, 2010; Daneman \& Capenter, 1980; Al-Hamadi, 2012; Alloway, Gathercole, Kirkhood \& Elliott 2009). In the African context, there has been no research thus far which empirically demonstrates a causal relationship between working memory capacity and reading skills in L1 and L2. As far as working memory is concerned, numerous studies have been conducted to evaluate students' performance with regard to their working memory, rather than cramming and remembering in order to measure comprehension, thereby revealing shortcoming in their understanding of basic recall information.

In order to understand reading development in L1 and L2, this research introduces studies that have used recall strategies to improve comprehension in participants in terms of their immediate memory that is, working memory. Working memory refers to a cognitive system devoted to the storage and processing of information during the performance of cognitive tasks (namely, reading in this case), and the processing of information previously stored during the process of reading (Snowling \& Hulme, 2007) in order to measure reading comprehension by rating the capacity of the participants. An individual's working memory capacity is usually assessed by using working memory span measures in which participants engage in online processing while maintaining information for later recall. For example, the study on working memory conducted by Daneman and Carpenter (1980) required that participants count the number of items in a series of arrays, and then recall the successive tallies of each array. In listening span activities, Daneman and Carpenter (1980) found that participants make judgements about the meaning of each of a series of sentences and then attempt to recall the final word of each sentence in sequence.

While research over the past 20 years has focused on participants recalling information from working memory (Daneman \& Capenter, 1980; Alloway, Gathercole, Kirkhood, \& Elliott, 2009; Andreassen \& Braten, 2010; and Lum \& Kidd, 2012), very little is mentioned about information recall as an on-line procedure of understanding reading comprehension rather than remembering specific words from a passage in order to use comprehension skills of participants to complete a recall test. Apart from a scant focus on reading challenges in Eritrea and some promising studies in South Africa, bilingual reading development in Sub-Saharan Africa is currently under-researched, and therefore also under-theorised as a guide for reading pedagogy in primary schools. This paper investigates reading development in L1 and L2 in order to provide a panoramic view of the reading levels of learners during recall testing.

\section{Current Studies on Recall}

Information recall has played a major role in developing comprehension. Gambrell, Pfeiffer and Wilson (1985) designed a study to investigate the effects of recall reading comprehension in order to examine whether recalling affects the processing of a text. Participants comprised 93 Grade 4 learners who were instructed to read a passage silently and complete the blanks. Upon completion of the free recall and the delayed recall exercises, learners had to answer 20 cued recall questions. Their results suggested that recalling is a highly effective generative learning strategy and that it has direct beneficial consequences on children's processing of textual information.

In addition, Alptekin and Ercetin (2010), used recall tasks to measure the participants' understanding of the participants by reading a comprehension passage. The study explored the role of $L 1$ and $L 2$ working memory capacities in L2 reading with proficient L2 users through reading span tests in L1 (Turkish) and L2 (English). Although the present study focuses on understanding rather than remembering what was read, the study conducted by Alptekin and Ercetin, (2010) is significant because it aids participants in remembering the important information; this in turn promotes an understanding of the information read, especially at tertiary level. The participants were first-year university students who were training to be teachers and came from homogenous backgrounds in terms of their level of performance. The students performed well during their entry tests which determined their levels of basic skills in academic language use. Their comprehension of the text was measured with a multiple choice test which contained a total of 20 questions relating 
to the readers' literal understanding, that is, their answers could be derived directly from the text. The participants were required to understand the message of the text by extracting meaning from the sentences and supplementing local inferences to make the text coherent. The results of the study suggest that L1 and L2 have a mutual relationship; hence, L1 performance determines L2 performance. The latter is evident from the given results indicating that if individuals have high storage capacities in L1, they are likely to have high storage capacities in L2 as well.

Contrary, to the above study, Chang (2006) focused his study on recall and translation, but nonetheless also included an element of comprehension, since participants were later expected to translate materials word for word. The participants were requested to read the texts as many times as they wished and to remember significant information in order to extract meaning since the texts would be surrendered during recall testing and handed back to them for the translation task. The data analysis revealed that the response rate and the accuracy rate of the translation task were higher than those of the immediate recall task in the reading passages. In conclusion, the process the participants had undergone contributed towards their understanding of the text, but less so in their remembering in terms of their accuracy rate.

Good (2009) conducted a similar study which focused on exploring whether providing a gloss could facilitate reading comprehension and vocabulary acquisition. Using recall, English speaking subjects had to write down everything they could remember in their L1 after reading an L2 text and subsequently they had to translate it into English. Three gloss conditions were investigated: L2 Spanish gloss, L1 English gloss and no gloss by providing subjects with a Spanish text. The results indicated no significant difference among the three conditions with regard to reading comprehension and vocabulary learning, although highly proficient participants who had glosses recalled more of the text while others performed well in the vocabulary translations tasks.

In further studies on recall, Connor (1984), asserted that comprehension and recall are determined both by the organisation of the text as well as by the sentence-level features. His study investigated the differences in the recall of a written English passage between first and second language readers. Speakers of English, Japanese and Spanish read a passage and wrote an immediate recall. The results of the study revealed that the native English speakers outperformed those who studied English as a Second Language (ESL) in terms of total recall. The L1 speakers recalled more prepositions than ESL participants and there was no significant difference in recall between the two groups of participants. Chu, Swaffar and Charney (2002) also used immediate and delayed recall by exploring whether culture specific rhetoric conventions affect the reading recall of Chinese students studying ESL; these students also completed a questionnaire and wrote an immediate recall test. After a week a delayed recall test was completed. Although, students failed to perceive any rhetoric differences, different conventions had a significant overall effect on their reading comprehension in both their immediate and delayed recall. In addition, Brantmeier (2005) used recall tasks to improve participants' L1 by measuring whether analogies facilitated learning and comprehension as measured by recall, sentence completion and multiple choice tests. To this end, participants wrote a recall test in their L1, irrespective of the language presented in the text. The results indicated no overall positive effect on the analogy of the text type on L1 and L2 comprehension as measured by recall. There were higher scores on the non-analogy version of both texts than on the analogy version when assessed by the recall test.

In addition to recall, a study on recognition memory (the ability to correctly remember something that has been encountered before) was conducted in order to measure the correlation between L1 and L2. It was discovered in the event of a mismatch (between information that was read/ acquired and information recalled) recognition did not occur (Finnegan et al, 2002). The said study comprising 73 fifth to seventh grade students in a Hebrew immersion programme in Canada found that correlations between two L2 working memory measures and L2 reading measures remained significant (Al-Hamadi, 2012).

As highlighted in the introduction, literature reviews on working memory indicate that an individual's working memory capacity has been used to assess working memory span measures in which participants engage in online processing materials while maintaining information for later recall during the process of cognitive tasks. For example, a study by Daneman and Carpenter (1980), even though it did not investigate the issue of information recall as a measure of $L 1$ and $L 2$ reading comprehension, is relevant to the present study since it required the participants to count the number of items in a series of arrays and then recall the successive tallies for each array consecutively. In the participants' views they were able to make judgements about the meaning of a series of sentences and then later attempted to recall the final word of each sentence in sequence. The present study focuses on the issue of recalling information. Recall in this study is defined in terms of understanding what was read and constructing meaning from the reading passage for later recall in order to answer the multiple questions posed. This study serves both as an online and offline study since the text was not removed from the learners while they were taking the test. 
This study is guided by both null and alternative hypotheses: (a) Will the school located in peri-rural area (School A) perform better in their English recall than in their Sepedi recall? (b) Will School $C$ located in the rural area perform better in their Sepedi recall than School B (rural "Selobedu") because the Semmamabolo dialect is very close to the standard variety? (c) Will Schools B and C both reveal the same level of performance in English since they are both based in a rural area? (d) Will dialectal differences in Schools B and C determine or influence how well learners perform?

\section{Methodology}

\subsection{Research context and participation}

The participants in this study comprised 150 Grade 7 learners selected from three different schools in Limpopo Province: Mankweng and Tzaneen. The mean age of the participants was 12.7 years. Grade 7 learners were chosen because they provide an ideal population to elucidate reading achievement rates of primary school learners in general. This is so, because this group of learners are in the final phase of their primary schooling.

The following criteria were used in selecting the schools: (a) rural and peri rural variation and (b) dialect-language gap. As a result, two schools using the same dialect and but a different reading context (rural, peri-rural) were identified in a large framework of over 20 possible primary schools in the Mankweng Circuit. It was in this framework that School A (peri-rural, Mmamabolo dialect) and School C (rural, Mmamabolo dialect) were identified and selected by means of a simple random sampling technique. The Mmamabolo dialect closely resembles Sepedi, the standard language variety used for educational purposes. For the purpose of this study, Sepedi was used instead of Northern Sotho. The selection of the second school was guided by criterion 2, a school with a different dialect. School B (rural, Selobedu dialect) was selected to meet criterion 2. Selobedu is mostly spoken by the community in Modjadjiskloof of Tzaneen. Learners stemmed from largely comparable families in terms of their social status, access to reading materials and levels of parent or caretaker education. School A had access to reading materials and their classrooms were print rich environments, while Schools B and C had limited opportunities. Grade 7 learners had been exposed to English as the Medium of Instruction (Mol) for only 2 years and 3 months, yet they were expected to master the skill of reading comprehension so that they could cope with the content structure in high school.

\subsection{Selection of Materials}

The reading materials were selected from the Provincial Department of Education for Grade 7. Narrative texts for L1 (Sepedi) and biographical texts for L2 (English) were preferred to other texts (e.g., transactional texts or expository texts) as it was assumed that both the former texts would be the writing genres that the learners would have been exposed to in Grade 7.

\subsection{Test}

Reading comprehension test: L1 (Sepedi) and L2 (English) reading comprehension was operationally defined as proficiency obtained in a reading comprehension test where a combination of test items was used for L1 (Narrative) and L2 (Biographic) texts. The reading passages were taken from various existing Grade 7 textbooks. Although the texts were different, learners Grade 7 level are expected to achieve $75 \%$ in reading comprehension as evidence that they have covered $95 \%$ of vocabulary knowledge. Therefore, the structure of the questions included a combination of a multiple choice questions of an inferential nature, vocabulary questions, and questions involving the identification of referents of anaphoric units.

Test administration: Both L1 (Sepedi) and L2 (English) reading comprehension tests were administered to learners in order to measure their reading levels with regard to information recall. Learners were afforded 25 minutes to complete each test. The L1 (Sepedi) test was administered first, and then followed by a break of 60 minutes before learners could write the L2 (English) test. The tests were written in the morning between $11 \mathrm{~h} 00$ and $13 \mathrm{~h} 00$, depending on the different schools. Learners completed the reading comprehension test by referring to the text for assistance with the understanding of the questions.

The stories were culturally appropriate for African Grade 7 readers. The Sepedi story focused on strengthening friendships, while the English story focused on youth career development. Each of the texts had a total of 400 words. The different texts, the same number of words and the different genres together ensured that the research questions of the study were well tested. The test was administered to the learners during the first month of the second quarter (April) and 
both the tests were administered on the same day with an interval of an hour between them. L1 (Narrative) was the first test to be written, followed by the L2 (Biographical) test after an interval of an hour.

\section{Data Analysis}

For the purposes of this study, the descriptive statistical procedure was used to measure and present the reading levels of learners and standard deviations were used as a measure of dispersion. Inferentially, descriptive statistics were used to assess the reading development of the learners when they were tested on reading comprehension using an information recall test. In all cases, a $95 \%$ confidence level was selected, pitched at an alpha value of 0.05 .

\section{Results}

The reading comprehension test measured information recall on Grade 7 learners in order to test their reading levels. The test was guided by the following research questions:

(1) Will the school located in the peri-rural area (School A) perform better in English recall than in Sepedi recall?

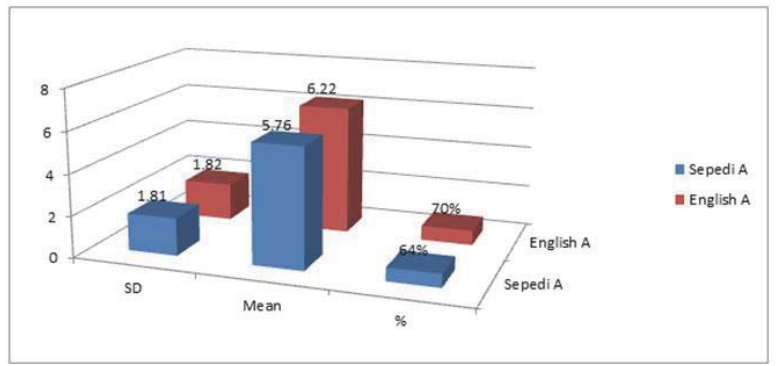

Figure 1: Reading levels in School A: Sepedi and English

It is evident from the graph in Figure 1, that the results are higher for English than for Sepedi (English: 70 \%; Sepedi 64 $\%)$. The mean score for both languages shows that the learners are incomparable. These results are supported by previous research (Pretorius \& Mampuru, 2007). The results of this study clearly indicate that learners do not possess developed recall skills with regard to their first language, which could be the results of less academic exposure to their first language at school.

This may also have been caused by under-developed vocabulary knowledge in the weaker learners. The standard deviation is approximately the same for both languages, with a differential mean of 5.76 for Sepedi and 6.22 for English. If learners perform better in English comprehension than in Sepedi comprehension, it suggests that they have not mastered Sepedi reading skills in a manner that matches their oral proficiency.

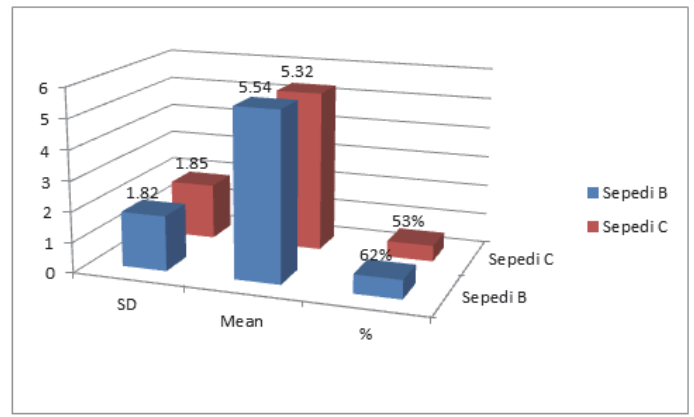

Figure 2: Reading levels for School B and C

Research question 2: Will School C, located in a rural area, perform better in Sepedi recall than School B (rural "Selobedu") because the Semmamabolo dialect is very close to the standard variety? This question examined the impact of dialect on learners who spoke Semmamabolo (close to the standard variety), and those who spoke Selobedu (dialect mostly spoken in Tzaneen: Modjadjiskloof). The data were analysed and the descriptive results revealed high test scores for the school were learners spoke Selobedu than for learners who spoke Semmamabolo. In support of the last research 
question 'dialect differences in Schools B and C will not determine or influence how well learners perform', the results suggest that irrespective of which dialect learners used, it does not have any influence on learning (e.g., Negative effect). This therefore implies that learners in School B are able to juggle between the dialect spoken in the community and the standard variety used at school and it can further suggest that there is a relationship between the spoken and written language of these learners.

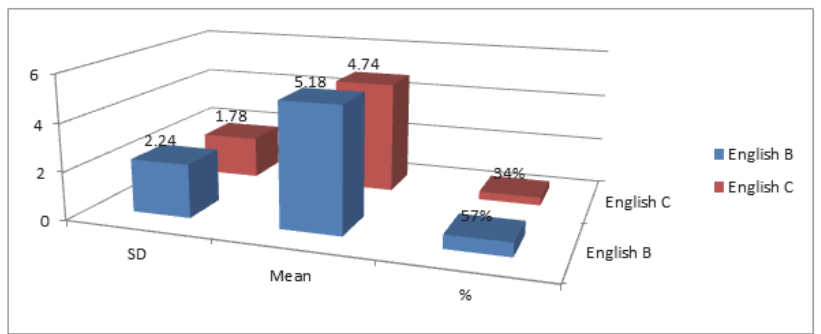

Figure 3: Reading level for School B and C: English

Research question 3: Will Schools B and C both reveal the same level of performance in English since they are both based in a rural area? This research question was posed in order to test the English reading levels of learners in both schools. It would be expected that if there is a difference in performance and with dialect not playing a role, the transfer of linguistic skills from L1 to L2 would require a well-developed first language. The results of the performance report, however, revealed that the first language background of the learners is not determined by the dialect they speak, since the dialect spoken by learners at School C contributes $50 \%$ to the standard variety, while the dialect spoken by learners at School B contributes $2 \%$ to the standard variety (Mojela, 2008:124). The results for School B report reading levels of $57 \%$ for English and low reading levels of $34 \%$ for School C. This therefore suggests that learners in School C have less vocabulary knowledge in comparison to learners in School B who yielded better results.

The main findings of the study suggest that, in general, learners who had difficulty comprehending the passage in Sepedi also performed poorly in English; similarly, learners who comprehended the English text better also did well in Sepedi. The results of the study supports the notion stated by Pretorius and Currin (2010), that 'the rich get richer and the poor get poorer', because weaker readers remain weak irrespective of the language they read, while the stronger learners perform well in both languages. The graph below (Figure 4) is a representation of the individual performance of learners in all schools, to show that most of the weak learners experienced difficulties in both languages and those who performed well did so in both languages.

\begin{tabular}{|c|c|c|c|c|c|}
\hline 1.00 & I.vo & o.vo & 4.00 & 1.0v & I.vo \\
\hline 7.00 & 7.00 & 7.00 & 4.00 & 6.00 & 7.00 \\
\hline 7.00 & 8.00 & 6.00 & 8.00 & 4.00 & 4.00 \\
\hline 5.00 & 4.00 & 8.00 & 6.00 & 7.00 & 5.00 \\
\hline 5.00 & 7.00 & 8.00 & 9.00 & 5.00 & 6.00 \\
\hline 5.00 & 8.00 & 8.00 & 9.00 & 3.00 & 4.00 \\
\hline 3.00 & 8.00 & 7.00 & 6.00 & 5.00 & 6.00 \\
\hline 5.00 & 6.00 & 6.00 & 4.00 & 8.00 & 4.00 \\
\hline 3.00 & 5.00 & 6.00 & 7.00 & 6.00 & 3.00 \\
\hline 4.00 & 2.00 & 5.00 & 4.00 & 4.00 & 3.00 \\
\hline 8.00 & 8.00 & 4.00 & 2.00 & 3.00 & 2.00 \\
\hline
\end{tabular}

Figure 4: Raw data for Schools A, B and C

The above graph presents raw data for the reading comprehension scores of the three schools. This is a representation of the data coded on the IBM SPSS Statistics 21 software on the spreadsheet. The first and second columns comprise data for School A, while the third and fourth columns presents data for School B and the last two columns list data are for School C. This graph demonstrates that learners who scored high marks in Sepedi also did so in English. The first, third and fifth columns indicates Sepedi reading scores, while the second, fourth and sixth column exhibit English reading scores. This further supports the finding that the weaker leaners are weak in both languages and the stronger learners are strong in both languages.

\section{Discussion and Conclusion}

The purpose of this study was to investigate reading comprehension among 7th graders when writing a recall test both in 
L1 and L2 in rural Limpopo, with learners being close to the mean age of 12.7 years. The descriptive results reveal that these learners do not represent a homogenous group because they are performing at different levels. This study is a representative of studies in various schools that falls within the same context as the schools under investigation. An issue that stands out in this study is the higher performance in L2 (English) compared with L1 (Sepedi) in School A with a score of $70 \%$. Conclusions cannot be drawn by this study with regard to Linguistic Interdependent Hypothesis $(\mathrm{LIH})$, since this theory does not apply for all the schools under investigation. The schools are not on the same reading levels, considering their different locations and availability of resources per school.

One of the findings of this study revealed that learners perform at different levels. Non-L1 readers in English were estimated to be able to read at $70 \%$ of the reading rate of L1 English readers. This suggests that the learners have experienced different reading opportunities. It can, however, be concluded from the results that achievements of $34 \%$ signify that learners are 3 years below their expected reading or proficiency comprehension level, achievements of $50 \%$ imply that they are 2 years below, and achievements of $70 \%$ indicate that learners are $5 \%$ below of the expected rate, since the reading comprehension test was pitched at $75 \%$ for Grade 7 . This could imply that South African learners are performing 2 years below their reading proficiency of $75 \%$; this is confirmed by the reading comprehension test results obtained from School C. Therefore, the results indicate that the reading proficiency of South African learners are at a developing stage, according to the results (schools that did not perform well) and in comparison with other developing countries (PIRLS 2006, ANA 2011).

Theoretically, the study results do not fit into the Linguistic Threshold Hypothesis (Cummins, 2000), which indicates that a certain level of vocabulary knowledge in the readers' home language enhances reading comprehension in the said language, whereas the lack of a similar threshold level in English makes it more difficult for reading comprehension to develop in English. Given these results, it was (LIH) that would be relevant for this study, and which advocates the transfer of skills from L1 to L2. However, this study did not show any evidence of a reading skills transfer from the home language (Sepedi) to English, therefore this finding requires further investigation.

According to Pretorius (2012), the majority of the Grade 6 learners in her study experienced difficulties in making sense of the text they read, irrespective of the language in which they read. There was, however, evidence of emergent literacy skills such as the ability to perceive sequence in text information, to make inferences from textual clues or even to make sense of graphic information in texts. The aforementioned results were also reflected in the current study: poor performance in reading comprehension which points to many factors and low proficiency in the language in which reading is conducted. All the learners were granted an opportunity to learn Sepedi as Language of Learning and Teaching (LoLT) in Grade 1 to 3, in theory at least. It is therefore appropriate to state that should these learners have enjoyed the advantage of initial reading instruction in their home language they would have performed well in their Sepedi comprehension test. The very weak Grade 7 learners in School C had poor reading comprehension (34\% in English and $53 \%$ in Sepedi), and found it difficult to successfully comprehend the material in order to complete the test. These were learners who came from a rural area whose school had no library at all, and who had achieved $34 \%$ in their home language.

The majority of these learners will be exiting their primary school education with a deficit, and few of these learners are likely to succeed in terms of the literacy demands of high school, especially moving from 'learning to read' to 'reading to learn' from content textbooks in the classroom (Pretorius \& Lephalala, 2011). A further speculation on the findings of this study is that the majority of the learners are still at a decoding level, which makes it difficult for them to actually integrate the reading comprehension test with a recall test on knowledge when they are presented with a text. Learners spend most of their time trying to read and spend less time on comprehension. Generally, Grade 7 readers need to be able to read both narratives and expository or information texts, as well as biographical texts so that they can 'read to learn' rather than 'learn to read' from their content subject textbooks.

Notably, recall is a reliable predictor of comprehension; therefore, learners are expected to comprehend and store information for later recall in order to enhance their later interaction with the text. Imbalanced bilingual reading seems to be a challenge to be addressed by re-thinking standards for a reading development trajectory. Therefore, there is a need for a balanced reading pedagogy as well as further to augment these findings. These reading outcomes offer suggestions for bi-literate development especially for schools with low reading achievement, where reading levels are low and reading is not part of the daily activities. Learners are therefore afforded adequate opportunities to take part in reading exercises both inside and outside schools.

\section{Acknowledgement}

The data reported in this article form part of my MA dissertation (at University of Limpopo) which was funded by VLIR 
(Vlaamse Interuniversitaire Raad) and supervised by Prof. Leketi Makalela. I want to thank UPSET (Understanding and Processing Languages in Complex Setting) and the Faculty of Humanities (North-West University-VTC) for financial support. A word of thanks further goes to anonymous reviewers and editor of the journal for their insight that made this manuscript to form part of the contributions in this journal.

\section{References}

Al-Hammadi, F.S. (2012). The role of recognition in L2 development. Languages and Translations, 24, 83-93.

Alloway, T. P., GATHERCOLE, S.E Kirkwood, H.J., Elliott, J. G. (2009). The Working Memory Rating Scale: A classroom-based behavioural assessment of working memory. Learning and Individual Differences, 19, 242-245.

Alptekin, C., \& Ercetin, C. (2012). Effects of Working Memory capacity and content familiarity of literal and inferential comprehension in L2 reading. Tesol Quarterly, $45(2), 235-266$.

Andreassen, R \& Braten, I. (2010). Examining the prediction of reading comprehension on different multiple-choice tests. Journal of Research in Reading. 33(3). 263-283.

Annual National Assessment. (2011). Department of Education: Basic Education. Pretoria. Department of Education annual report.

Asfaha, Y.M., Bechman, D., Kurvers, J., \& Kroon, S. (2009). L2 reading in multilingual Eritrea: The influence of L1 reading and English proficiency. Journal of Research in Reading, 32 (4), 351-365.

Bernhardt, V. (1998). Data analysis for comprehensive school-wide improvement. Larchmont, NY: Eye on Education, Inc.

Brantmeier, C.(2005). Effects of readers' knowledge, text type and test type on L1 and L2 reading comprehension in Spanish. The Modern Language Journal, 89 (1), 37-53.

Chu, H.J., Swaffar, J., \& Charney, D.H. (2002). Cultural representation of rhetoric conventions: The effects on reading recall. Tesol Quarterly, 36 (4), 511-541.

Chung, Y. (2006). On the use of immediate recall task as a measure of second language reading comprehension. Language Testing, 23:520.

Connor, U. (1984). Recall of text: Differences between first and second language readers. TESOL QUARTERLY, 18 (2), 239-256.

Cuenca-Sanchez, Y. (2008). A literature review: English Language learners and reading comprehension. George Mason University.

Cummins, J. (1979). Linguistic Interdependence and the educational of developmental bilingual children. Review of Educational Research, 49(2), 222- 51.

Cummins, J. (2000). Language power and pedagogy: Bilingual children in the cross-fire, Clevedon: Multilingual Matters.

Daneman, M., \& Carpenter, P.A (1980). Individual differences in working memory and reading. Journal of Verbal Learning and Verbal Behaviour, 19, 450-466.

Finnegan S, Humphreys, M.S., Dennis, S., Geffen, G. (2002). ERP 'old/new' effects memory strength and decisional factor(s). Neuropsychology, 40 (13), 2288-2304.

Gambrell, L.B., Pfeiffer, W.B., Wilson, R.M. (1985). The effects of retelling upon reading comprehension and recall of text information. The Journal of Educational Research, 78 (4), 216-220.

Garcia, O. (2007). Bilingual Education in the 21st Century: A Global Perspective. New York: Wailey-Blackwell.

Good, R.L.(2009). L1 glosses: Effects on EFL learners' reading comprehension and vocabulary retention. Reading in a Foreign Language, 21 (2), 119.142.

Lum, J., \& Kidd, E.(2002). An examination of the association among multiple memory Systems, past tense, and vocabulary in typically developing 5 year-old children.Journal of Speech, Language and Hearing Research.55, 989-1006.

Mclaughlin, M. L. (1984).Conversation: How talk is organized. Sage Series in Interpersonal Communication 3. Beverly Hills: Sage Publications.

Mojela, V.M.(2008). Standardization or Stigmatization? Challenges confronting lexicography and terminography in Sesotho sa Leboa. Lexicos 18, 119-130.

National Reading Panel. (2002). Teaching children to read: An evidence-based assessment of the scientific literature on reading and its implication for reading instruction. Washington, DC: US Government Printing Office.

Paran, A., \& Williams, E. (2007). Editorial: Reading and literacy in developing countries. Journal of Research in Reading, 30 (1), 1-6.

Pretorius, E.J., \& Mampuru,D.M. (2007). Playing football without a ball: Language, reading and academic performance in a higherpoverty school. Journal of Research in Reading, 30, 23-37.

Pretorius, E.J., \& CURRIN, S.V. (2010). Do the rich get richer and the poor poorer? The effect of an intervention programme on reading in the home and school language in a higher poverty multilingual context. International Journal of Education Development, 30, 67-76.

Pretorius, E.J., \& Lephalala, M. (2011). Reading comprehension in high-poverty Schools: How should it be taught and how well does it work? A Journal of Language Learning, 27 (2), 1-24.

Pretorius, E.J. (2012). Butterfly effect in reading? The relationship between decoding and comprehension in Grade 6 high poverty schools. Journal of Language and Teaching. 46 (2), 74-95.

Schmitt, N. X, Jiang. W, Grabe. (2011). The percentage of words known in a text and reading comprehension. Modern Language Journal. 95(1).

Sisulu, E. (2004). A reading family. Accessed on September17, 2010 from www.teacher.co.za/9909/literacy2.html.

Snowling, M.J., \& Hulme, C. (2007). The science of reading. A handbook of Developmental Psychology. Blackwell publishing Ltd. 